PRODUTO \& PRODUÇÃO, vol. 22, n.1, 67-97, 2021*

PP

\title{
Análise bibliométrica sobre o uso da CFD em vortex tube no período entre 2000 e 2020
}

\section{Bibliometric analysis regarding the use of CFD in vortex tube during the period from 2000 to 2020}

\author{
Danillo Lanzieri Modesto \\ Instituto de Pesquisas Tecnológicas do Estado de São Paulo \\ danillomodesto@yahoo.com.br \\ Efraim Cekinski \\ Instituto de Pesquisas Tecnológicas do Estado de São Paulo \\ cekinski@gmail.com
}

\begin{abstract}
Resumo
O objetivo deste trabalho é verificar o volume de produção científica, dentro do tópico de engenharia nos últimos vinte anos, as abordagens acerca do tubo de vórtice de Ranque-Hilsch simulado por meio da fluidodinâmica computacional (CFD). Foi aplicado como metodologia a Lei de Bradford para análise de produtividade com um sequenciamento progressivo dos resultados obtidos, constando desde a definição de uma base de coleções de periódicos para avaliar qual é a que apresenta o maior volume de publicações a respeito do tema proposto até na investigação mais profunda para encontrar o material mais citado, quais autores têm apresentado maior contribuição no meio e também quais foram os mais citados dentro desta base de coleção. Com isto, foi possível constatar que a combinação mais utilizada, que são a de "vortex tube" e "CFD", possui uma média de 1,35 publicações por ano e ainda evidencia uma diminuição na quantidade de publicações desde 2016.
\end{abstract}

Palavras-chave: tubo de vórtice; tubo de vórtice de Ranque-Hilsch; CFD

\begin{abstract}
The aim of the present paper is to investigate the quantity of scientific production, within the engineering topic in the last twenty years, the approaches about the Ranque-Hilsch Vortex Tube simulated by means of Computational Fluid Dynamics (CFD). The Bradford Law for productivity analysis was used as a methodology with a progressive sequencing of the results obtained, consisting of the definition of a base of journals to assess which is the one with the largest number of publications regarding the theme proposed even in the most in-depth investigation to find the most cited material, which authors have made the greatest contribution and also which were the most cited within this collection base. With this, it was possible to verify that the most used combination, which is "vortex tube" and "CFD", has an average of 1.35 publications per year and still shows a decrease in the number of publications since 2016.
\end{abstract}

Keywords: vortex tube; Ranque-Hilsch vortex tube; CFD

\footnotetext{
*RECEBIDO EM 26/07/2020. ACEITO EM 06/09/2020.
} 


\section{Introdução.}

Cada vez mais estudos buscam a otimização no desempenho e recuperação energética em todas as escalas, seja em máquinas, equipamentos, residências, plantas industriais, veículos automotores, dentre outros. Em um âmbito mais social, a eficiência energética pode ser um meio fundamental para alcançar a sustentabilidade.

Este não é um cenário recente, mesmo que essas mudanças tenham sido mais intensas e rápidas nos dias atuais com o uso mais frequente de computadores e automatização de sistemas, recursos estes que ainda consomem energia. O desafio tem sido justamente em aumentar o desempenho destes sistemas de modo a consumir o mínimo de energia possível.

Neste contexto, um dispositivo chamado RHVT (Ranque-Hilsch Vortex Tube, em inglês), também conhecido como tubo de Ranque-Hilsch ou simplesmente tubo de vórtice, tem sido objeto de estudo por oferecer uma alternativa aos meios atuais de obtenção de uma corrente de ar fria e quente a partir de um mecanismo tecnicamente simples. O nome do dispositivo é devido a homenagem a estes dois pesquisadores por suas descobertas, Ranque foi o primeiro a inventar o método e o dispositivo em 1934, e Hilsch, em 1946, o primeiro a aperfeiçoar essa proposta.

Desde a sua invenção o RHVT é o interesse de pesquisa de diversos estudiosos, pois ainda não existe uma teoria muito clara de como o fenômeno da transformação de energia dentro deste equipamento ocorre (DÖRR, 2017).

Para Itao (2005), a determinação do mecanismo do fenômeno de Ranque-Hilsch tem gerado uma grande disputa ao longo dos anos. Como Kurosaka $(1982)^{\dagger}$, onde apresenta uma teoria em que ondas acústicas induzem distúrbios ordenados dentro do fluxo espiral em tal nível, de forma a causar a separação energética. Stephan et al. (1983), que realizaram um estudo do processo de separação energética cujo resultado mostrou a distribuição da variação de temperatura de fluxo de ar de baixa temperatura ao longo do comprimento da câmara do tubo de vórtice. Alhborn et al. (1994) desenvolveram um estudo focado na influência da energia cinética nos fluxos de ar quente e frio sendo expulsos do tubo de vórtice. Saidi e Yazdi (1998) ${ }^{* *}$ estudaram a obtenção de dimensões e condições de operação otimizada, aplicando a abordagem de análise de exergia.

Bazgir, Khosravi-nikou e Heydari (2019) também categoriza tantos outros autores que têm se dedicado em pesquisar diversos aspectos do tubo de vórtice, conforme apresentado na Tabela 1.

Tabela 1 - Visão geral da literatura sobre os estudos em tubo de vórtice

\begin{tabular}{l|c|l}
\hline \multicolumn{1}{c|}{ Autor } & Ano & \multicolumn{1}{c}{ Pesquisa } \\
\hline Ranque & 1933 & Primeira separação de temperatura em tubo de vórtice \\
\hline Hilsch & 1946 & $\begin{array}{l}\text { Primeiro estudo detalhado dos parâmetros de separação de } \\
\text { temperatura em tubo de vórtice }\end{array}$ \\
\hline Knoernschild & 1948 & Explicação do efeito Ranque-Hilsch \\
\hline Elser e Hoch & 1951 & Separação dos gases em tubo de vórtice \\
\hline Deissler e Perlmutter & 1960 & Análise da separação de energia \\
\hline Reynolds & 1961 & Mecanismo da separação de energia \\
\hline Erdelyi & 1962 & Explicação do efeito Ranque-Hilsch \\
\hline Sibulkin & 1962 & Fluxo circular instável, viscoso \\
\hline
\end{tabular}

$\dagger$ apud ITAO, 2005

$\ddagger$ apud ITAO, 2005

$\S$ apud ITAO, 2005

** apud ITAO, 2005 


\begin{tabular}{|c|c|c|}
\hline Gulyaev & 1965 & Efeito Ranque-Hilsch em baixas temperaturas \\
\hline Bruun & 1969 & Separação experimental de energia em tubo de vórtice \\
\hline Linderstrom-Lang & 1971 & Cálculos 3D de velocidade e temperatura em tubo de vórtice \\
\hline Takahama e Yokosawa & 1981 & Separação de energia divergente em tubo de vórtice \\
\hline Kurosaka & 1982 & Corrente acústica em fluxo turbulento \\
\hline Stephan et al. & 1983 & Investigação experimental de separação de energia \\
\hline Stephan et al. & 1984 & Formulação matemática da separação de energia \\
\hline Eckert & 1986 & Separação de energia em tubo de vórtice \\
\hline Balmer & 1988 & Efeito de Ranque-Hilsch em líquidos \\
\hline Ahlborn et al. & 1994 & Limites de separação de energia \\
\hline Ahlborn e Groves & 1997 & Fluxo secundário em tubo de vórtice \\
\hline Gutsol & 1997 & Revisão do efeito de Ranque-Hilsch \\
\hline Gutsol e Bakken & 1998 & Explicação do efeito Ranque-Hilsch \\
\hline Fröhlingsdorf et al. & 1999 & Análise CFD do tubo de vórtice (padrão k- $-\varepsilon$ ) \\
\hline Mischner e Bespalov & 2002 & Produção de entropia em tubo de Ranquel-Hilsch \\
\hline Shannak & 2004 & Separação de temperatura em tubo de vórtice \\
\hline Aljuwayhel et al. & 2005 & Estudo numérico do tubo de vórtice (RNG k- $\varepsilon$, padrão k- $-\varepsilon$ ) \\
\hline Behera et al. & 2005 & Estudo numérico de RHVT (RNG k- $-\varepsilon)$ \\
\hline Gao et al. & 2005 & Estudo experimental de RHVT \\
\hline Piralishvili e Fuzeeva & 2005 & Estudo analítico e experimental de RHVT \\
\hline Piralishvili e Fuzeeva & 2006 & Critérios para separação de energia \\
\hline Sky et al. & 2006 & Estudo numérico do tubo de vórtice (RNG k- $\varepsilon$, padrão k- $\varepsilon$ ) \\
\hline Sohn et al. & 2006 & Estudo experimental e numérico do tubo de vórtice \\
\hline Eiamsa-ard e Promvonge & 2006 & Estudo numérico do tubo de vórtice \\
\hline Eiamsa-ard e Promvonge & 2007 & Estudo numérico de RHVT \\
\hline Eiamsa-ard e Promvonge & 2008 & Revisão do RHVT \\
\hline Dincer et al. & 2008 & Estudo experimental de RHVT \\
\hline Behera et al. & 2008 & Estudo numérico de RHVT (RNG k- $-\varepsilon$ ) \\
\hline Xue e Arjomandi & 2008 & Efeito do ângulo de vórtice no RHVT \\
\hline Yilmaz et al. & 2009 & Revisão sobre os critérios de projeto para tubo de vórtice \\
\hline Secchiaroli et al. & 2009 & Estudo numérico de RHVT (RANS e LES) \\
\hline Zin et al. & 2010 & Estudo numérico de tubo de vórtice (RNG k- $-\varepsilon$ ) \\
\hline Xue et al. & 2010 & Revisão da separação de temperatura \\
\hline Xue et al. & 2013 & Estudo experimental de separação de temperatura \\
\hline Liu et al. & 2014 & Estudo numérico de tubo de vórtice (padrão k- $-\varepsilon$ ) \\
\hline Xue et al. & 2014 & Análise de energia em tubo de vórtice \\
\hline Kobiela & 2014 & $\begin{array}{l}\text { Derivação analítica do efeito de Ranque-Hilsch a partir das } \\
\text { equações de conservação }\end{array}$ \\
\hline Thakare et al. & 2015 & $\begin{array}{l}\text { Revisão de estudos experimentais, numéricos e de otimização } \\
\text { de tubo de vórtice }\end{array}$ \\
\hline Manimaran & 2016 & Análise computacional da separação de energia \\
\hline
\end{tabular}




\subsection{Tubo de Ranque-Hilsch (RHVT)}

Ainda que o funcionamento do tubo de Ranque-Hilsch seja pouco conhecido, sabe-se como é o comportamento da corrente de ar em seu interior, isto não necessariamente é um paradoxo, pois de forma empírica tem-se adquirido ótimos resultados, mas sem muito conhecimento de como isto ocorre, assim, podemos caracterizá-lo como uma técnica para obter uma separação de duas correntes com diferentes temperaturas.

Para o próprio Ranque (1934), precursor do dispositivo, o método de sua invenção consiste essencialmente em dividir o fluido sob pressão, que é admitido tangencialmente em um vaso com a forma de um corpo cilindro, em duas camadas coaxiais que se movem com um movimento giratório e reagem umas às outras, de modo a produzir, sob o efeito da força centrífuga, a compressão da camada externa pela camada interna que se expande, absorvendo uma certa quantidade de trabalho, o que é evidenciado pelo aumento da temperatura da camada compactada em detrimento da outra camada, que é, portanto, resfriada.

A Figura 1 apresenta o funcionamento e as partes que compõem um tubo de vórtice de contrafluxo, que é o modelo mais comumente encontrado.

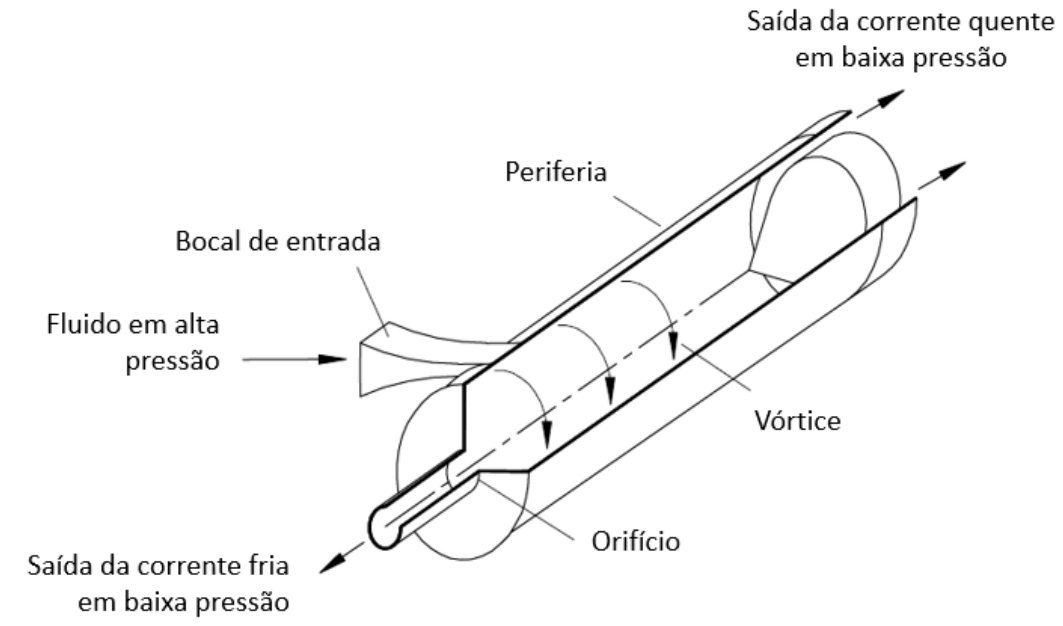

Figura 1 - Funcionamento e composição de um tubo de vórtice de contrafluxo. Adaptada de Aljuwayhel, Nellis e Klein (2005)

De modo prático, o fluido sob pressão é injetado tangencialmente em um corpo cilíndrico provido de orifícios axiais dispostos em ambos os lados da entrada. O fluido é então "guiado" de modo a proporcionar um movimento helicoidal em direção a um destes orifícios, cuja seção transversal é adequadamente restrita a fim de produzir um movimento para trás de uma porção do fluido em direção ao orifício oposto. Isso produz duas camadas de fluidos com movimentos axiais opostos, a camada interna expandindo e comprimindo a camada externa, fornecendo calor à mesma. Uma corrente de fluido quente é assim recebida através do orifício de seção transversal restrita, enquanto uma corrente de fluido frio é recebida através do orifício oposto (RANQUE, 1934).

Para Maragon (2016), desde sua descoberta por Ranque, o tubo de vórtice tem sido um objeto de interesse, tanto do teórico quanto no prático. O efeito da separação energia ou da estratificação de temperatura e outros efeitos provenientes de tubos de vórtice lhes permitem ser amplamente utilizados para os diferentes fins. O tubo de vórtice tem muitas vantagens o que os torna muito atraentes para aplicações industriais.

Hoje, conhecido como RHVT, muitos pesquisadores buscam aprimorar seu desempenho e cada vez mais, sua geometria ainda está obscura, pois é quase impossível provar por cálculos matemáticos, 
seu funcionamento (SOUZA, 2009) $)^{\dagger \dagger}$. A grande questão é que as suas características construtivas não possuem quaisquer equipamentos elétricos ou mecânicos para conseguir separar um fluxo de entrada em dois fluxos distintos, ou seja, Hilsch conseguiu provar que um fluxo de ar com uma temperatura de $20{ }^{\circ} \mathrm{C}$ poderá ser transformada em um fluxo de $70{ }^{\circ} \mathrm{C}$ e outro a $-12{ }^{\circ} \mathrm{C}(\mathrm{HILSCH}, 1947)^{+1}$.

Estudos como os de Yilmaz et al. (2009), listam valores ótimos para um melhor desempenho do RHVT. Sua revisão inclui definições importantes, classificação e estudo paramétrico do tubo de vórtice, trabalho experimental e qualitativo, analítico e numérico, mas apesar desta profunda pesquisa, enfatizam que é difícil projetar um tubo de vórtice com características integrais definidas para uma aplicação concreta, uma vez que os dados experimentais disponíveis não estão claramente entendidos e não há generalizações totalmente corretas.

De acordo com Dörr (2017), durante muitos anos o tubo de vórtice se mantém como objeto de pesquisa para diversos profissionais de áreas em que há interesse em obter uma maneira de separação de temperaturas, sem haver a necessidade de nenhum componente móvel em sua construção e sem nenhum tipo de reação química no seu interior. Desde a sua invenção por Georges Joseph Ranque, em 1934, a geometria do RHVT sofreu poucas alterações e também poucas variações nos resultados até então registrados.

\subsection{Tubo de Ranque-Hilsch (RHVT) e a fluidodinâmica computacional (CFD)}

De acordo com Murakami (2010), existe na literatura científica uma grande variedade de métodos numéricos para solução de problemas de Engenharia. Como exemplos, podem ser citados: Método de Diferenças Finitas (MDF), Método dos Elementos Finitos (MEF), Método dos Volumes Finitos (MVF), etc.

O MDF (Método das Diferenças Finitas) sempre foi empregado pelos analistas da área de escoamento de fluidos, enquanto o MEF (Método dos Elementos Finitos) o foi para a área estrutural, na solução de problemas de elasticidade. Os problemas de escoamento são altamente não-lineares, enquanto os da elasticidade não possuem os termos convectivos, não lineares, e assemelham-se a problemas puramente difusivos de transferência de calor (FRANCO, 2001) ${ }^{\S \S}$.

O método de Diferenças Finitas, atualmente, pode ser utilizado em qualquer tipo de malha, mesmo a não-estruturada usada em elementos finitos. O MVF (Método dos Volumes Finitos) garante a conservação da propriedade envolvida (massa, quantidade de movimento e entalpia) no volume elementar, e é preferível em relação ao MDF. Na atualidade, ambos os métodos (MVF e MEF) estão resolvendo problemas altamente convectivos, inclusive com ondas de choque, em geometrias arbitrárias. Isto é esperado, visto que, eles são derivados do mesmo princípio e diferem apenas na forma de minimização escolhida (FRANCO, 2001) ${ }^{* * *}$.

A metodologia CFD (sigla em inglês para Computation Fluid Dynamics) utiliza o esquema numérico baseado no Método dos Volumes Finitos, o qual consiste na discretização do domínio em inúmeros volumes de controle sobre os quais são realizados balanços de massa, quantidade de movimento e energia a partir da solução das equações diferenciais parciais, para a predição quantitativa

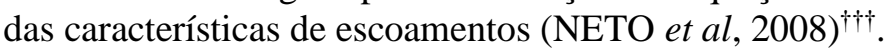

Sendo assim, é possível conhecer melhor o funcionamento do RHVT por meio de softwares de simulações computacionais, que permitem a realização de cálculos numéricos a partir de modelos matemáticos que proporcionam resultados mais precisos e rápidos das simulações. Essa é uma maneira

\footnotetext{
$\dagger^{\dagger}$ apud MARAGON, 2016

拉 apud MARAGON, 2016

$\S \S$ apud MURAKAMI, 2010

${ }^{* * *}$ apud MURAKAMI, 2010

$\mathrm{t \dagger †}^{\dagger}$ apud MURAKAMI, 2010
} 
eficiente de se criar uma versão fidedigna de uma estrutura, sistema ou componente antes de submetêlo a testes experimentais reais em laboratório, além de ser um recurso com menor custo comparado aos métodos de tentativa e erro de sua construção física. Dentro dos diversos métodos computacionais disponíveis, está a fluidodinâmica computacional, conhecida também como CFD, que consiste em uma análise de sistemas envolvendo o fluxo de fluidos, transferência de calor e seus fenômenos associados, tais como reações químicas, como já detalhado anteriormente.

De acordo com Eiamsa-ard e Promvonge (2008), a maioria dos trabalhos anteriores, baseados em estudos teóricos e analíticos antes da aplicação da técnica de CFD, não obtiveram êxito para explicar o fenômeno da separação de energia no tubo. Assim, os autores compilaram diversos resultados de pesquisadores que analisaram, por meio da CFD, alguns modelos de RHVT.

Já Bazgir, Khosravi-nikou e Heydari (2019), demonstraram como o uso de diferentes modelos de turbulência pode afetar o descolamento de temperatura dentro do RHVT. Assim, observa-se que aplicando a técnica CFD em um modelo de RHVT, permite-se conhecer mais detalhadamente os fenômenos que acontecem enquanto o fluido é injetado em seu interior, Deste modo, torna-se possível analisar novas maneiras a fim de obter resultados mais eficientes, pois ainda é relativamente considerável o consumo de ar comprimido para obter valores significativos na corrente fria.

Portanto, esta análise bibliométrica propõe apresentar as bases de coleção de periódicos os quais mais têm publicado assuntos que abordem o tema de tubo de vórtice associado a fluidodinâmica computacional, assim como os autores quem mais contribuíram e também os mais citados no meio.

\section{Metodologia.}

A metodologia aplicada para a seleção referencial bibliográfico utilizada no presente trabalho foi a Lei de Bradford com complemento de uma sequência progressiva, ou seja, a medida em que os resultados eram obtidos a partir da apuração feita pela Lei de Bradford, foi seguido um aprofundamento dos principais resultados.

A lei de Bradford relaciona a dispersão de artigos por periódicos. Ela considera que poucos periódicos contém uma concentração de artigos relevantes de determinada área, e muitos periódicos possuem poucos artigos sobre determinada área (NICOLAISEN; HJORLAND, 2007)

O objetivo desta lei é descobrir a distribuição de artigos nos periódicos, com isso é possível determinar o periódico mais relevante sobre um determinado tema para facilitar a busca de artigos na composição da revisão de literatura ou encontrar periódicos para publicação (ARAUJO, 2006) ${ }^{\S \S}$.

Para Pinheiro, Chalhub e Nisenbaum (2013), a Lei de Bradford, originalmente utilizada para análise de produtividade de periódicos, é uma das principais leis bibliométricas. Essas leis estão relacionadas a duas variáveis: conjunto de produtores (autores, artigos, periódicos, assuntos), e conjunto de produtos (documentos, periódicos, citações).

De acordo com a formulação da Lei de Bradford, pode ser estabelecido um número variável de zonas de produtividade de determinado fenômeno, basicamente três: de alta frequência ou núcleo, de média e de baixa frequência ou de dispersão (PINHEIRO; CHALHUB; NISENBAUM, 2013).

Ao citar o enunciado da Lei de Bradford, Pinheiro (1982) destaca: "se os periódicos forem ordenados em ordem de produtividade decrescente de artigos sobre um determinado assunto, poderão ser distribuídos num núcleo de periódicos mais particularmente devotados a esse assunto e em diversos grupos ou zonas contendo o mesmo número de artigos que o núcleo, sempre que o número de periódicos e das zonas sucessivas for igual a 1:n:n²...”. A Figura 2 apresenta a formulação gráfica da Lei de Bradford.

¥¥† apud QUEVEDO-SILVA et al., 2016

§§§ apud QUEVEDO-SILVA et al., 2016 


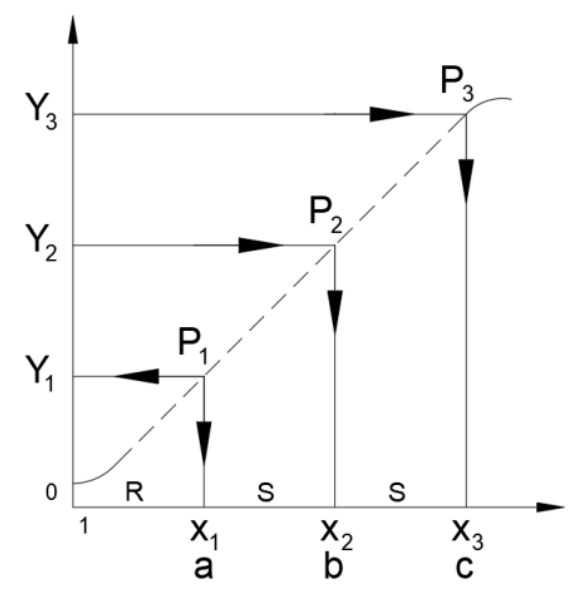

Figura 2 - Formulação gráfica da Lei de Bradford. Adaptada de Pinheiro (1982)

De acordo com o próprio Bradford, a parte inicial correspondente à concentração (Zona a); a do meio, de produtividade média (Zona b) é a componente de Zipf e a terceira (Zona c), compreende os periódicos de baixa produtividade - de dispersão e queda de Groos (PINHEIRO, 1982).

Complementarmente, foi adotado também uma sequência progressiva a partir dos resultados pela Lei de Bradford. A Figura 3 apresenta o fluxo desse sequenciamento.

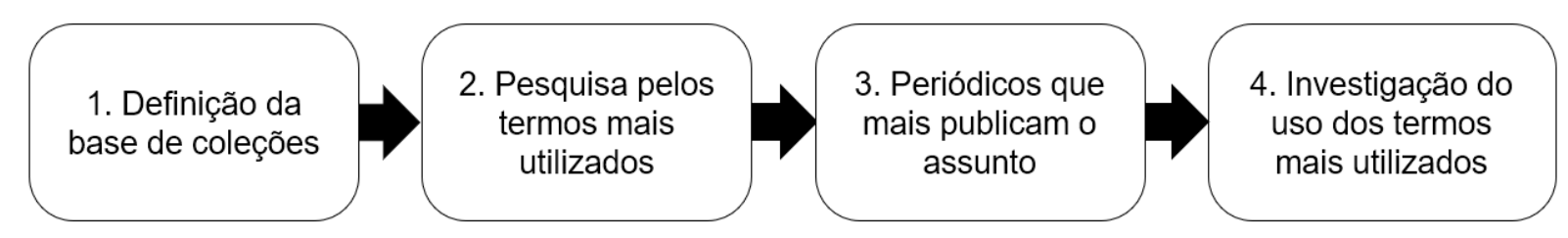

Figura 3 - Sequência utilizada para o levantamento bibliométrico. Elaborada pelos autores

I. "Definição da base de coleções" é a primeira etapa. Nesta, a pesquisa foi realizada junto à biblioteca virtual do Portal de Periódicos da Coordenação de Aperfeiçoamento de Pessoal de Nível Superior (CAPES) do Ministério da Educação do Governo do Brasil (BRASIL, 2020). Munido da relação de coleções que compreendem os termos pesquisados, foi então aplicado a Lei de Bradford para determinar as que tiveram contribuições mais significativas. Os critérios estabelecidos para a busca da base de coleções foram entre o período de 01 de janeiro de 2000 a 05 de junho de 2020, limitado ao tópico "Engineering" e por periódicos revisados por pares. Os parâmetros de pesquisa para determinar a base de dados foi a seguinte sintaxe de busca no título: “'RHVT' OR 'VORTEX TUBE' OR 'Ranque-Hilsch' AND ‘CFD””.

II. Em "Pesquisa pelos termos mais utilizados", já na base definida, buscou-se averiguar quais são os termos mais utilizados pelos autores acerca do assunto abordado. Nesta etapa, além de experimentar termos isolados, também foram pesquisados por termos compostos.

III. No item "Periódicos que mais publicam o assunto" busca apurar as fontes mais dedicadas ao tema.

IV. "Investigação do uso dos termos mais utilizados" trata de analisar quais são os principais autores que fazem uso destes termos e quais são os artigos mais citados com estes mesmos termos em seus conteúdos, além de analisar quais são os autores mais frequentes dentro das publicações mais citadas. Foi utilizado o VOSviewer versão 1.6 .15 como ferramenta para imprimir os mapas de densidade e relacionamento. 
Moreira, Guimarães e Tsunoda (2020) realizaram uma comparação entre softwares que auxiliam no processo de seleção das ferramentas adequadas para pesquisas bibliométricas, e a partir de uma lista com dezesseis ferramentas apresentadas em publicações precedentes, foram selecionadas quatro soluções com base em critérios de exclusão predefinidos pelos próprios autores: versão recente, interface gráfica e livre para utilização. A Tabela 2 apresenta as dezesseis ferramentas pré-selecionadas, que tomou-se como base artigos elaborados por Cobo et.al, $(2011,2012)^{* * * *}$ e McLevey e Mcllroy-Young $(2017)^{\dagger \dagger \dagger}$, por serem trabalhos que apresentavam comparações entre ferramentas bibliométricas e a lista de softwares bibliométricos e de colaboração científica presente no Portal da Escrita Científica, da Universidade de São Paulo (USP), campus São Carlos.

Tabela 2 - Lista de ferramentas bibliométricas

\begin{tabular}{l|l}
\hline \multicolumn{1}{c|}{ Ferramenta } & \multicolumn{1}{c}{ Referência } \\
\hline Bibexcel & Persson, Danell e Schneider (2009) \\
\hline Bibliometrix/Biblioshiny & Aria e Cuccurullo (2017) \\
\hline CiteSpace & Chen (2006) \\
\hline CoPalRed & Bailón-Moreno, Jurado-Alameda e Ruiz-Baños (2006) \\
\hline IN-SPIRE & Pacific Northwest National Laboratory (2019) \\
\hline InCites & Clarivate Analytics (2019) \\
\hline Leydesdorff's Software & - \\
\hline Metaknowledge & Mclevey e Mcilroy-Young (2017) \\
\hline Network Workbench Tool & NWB Team (2006) \\
\hline Publish or Perish & Harzing (2007) \\
\hline Science of Science (Sci²) Tool & Sci² Team (2009) \\
\hline SCImago & SCImago (2019) \\
\hline SciMAT & Cobo et al. (2012) \\
\hline SciVal & Elsevier (2019) \\
\hline VantagePoint & Porter e Cunningham (2005) \\
\hline VOSViewer & Van Eck e Waltman (2009) \\
\hline
\end{tabular}

Fonte: Moreira, Guimarães e Tsunoda (2020)

Dentro dos critérios de triagem de Moreira, Guimarães e Tsunoda (2020), os quatro principais softwares para desenvolvimento de bibliometria são: Biblioshiny, VOSviewer, Publish or Perish e CiteSpace.

Destes, o Biblioshiny apresenta o maior número de possibilidades em análises, embora apresente limitações nos relatórios visuais. O VOSviewer adota uma interface limpa e simples focada na visualização de redes bibliométricas. O Publish or Perish exibe a maior restrição em relação aos critérios comparativos, mas sua integração com o Google Acadêmico lhe confere vantagem em relação aos demais. Por fim, o CiteSpace oferece uma grande quantidade de parâmetros para formar suas visualizações de redes, mas sua interface desorganizada prejudica a experiência dos usuários (MOREIRA; GUIMARÃES e TSUNODA, 2020).

Ainda de acordo com Moreira, Guimarães e Tsunoda (2020), o Biblioshiny apresenta praticamente todas as análises presentes no VOSviewer, porém conta com severas restrições de personalização no visual das redes formadas, sendo indicada a exportação dos dados para outras ferramentas para um resultado mais apurado.

\footnotetext{
**** apud MOREIRA; GUIMARÃES e TSUNODA, 2010

†††† apud MOREIRA; GUIMARÃES e TSUNODA, 2010
} 
O ponto forte do VOSviewer se concentra na visualização de redes. Ainda assim, antes da visualização do mapa, é possível verificar os dados processados, em formato de tabela que pode ser exportado para outros programas, possibilitando novos tipos de análise. De qualquer maneira, o VOSviewer se caracteriza como uma ferramenta típica da etapa de visualização dos resultados (MOREIRA; GUIMARÃES e TSUNODA, 2020).

A ferramenta VOSviewer foi desenvolvida por Nees Jan van Eck e Ludo Waltman, da Leiden University, na Holanda, e provê uma interface de fácil utilização para visualizar e analisar redes bibliométricas e sociométricas, coautoria, citação, cocitação, acoplamento bibliográfico e coocorrência de palavras-chave, servindo tanto a pesquisadores quanto a usuários profissionais, como agências de financiamento de pesquisas e editoras científicas (LIMA; LEOCÁDIO, 2018).

Apesar do VOSviewer ser considerado uma poderosa ferramenta, além da disponibilidade para download de forma gratuita, é capaz de contribuir significativamente para uma eficiente análise bibliométrica, optou-se por utilizar não somente o VOSviewer neste trabalho, mas sim como complemento ao método convencional de análise e impressão de gráficos. Pois, a medida em que foram feitas as buscas, observou-se que eram retornados pouquíssimos resultados e que ficavam dispersos e pouco apresentáveis quando gerado seus mapas de densidade e relacionamento. 


\section{Resultados e Discussões.}

\subsection{Definição da base de coleções.}

A Tabela 3 está ordenada, de forma decrescente, pela quantidade de produção, segundo a biblioteca de periódicos da CAPES, nela também é apresentada as definições de Zonas de acordo com a Lei de Bradford.

Tabela 3 - Principais bases de coleções com maior número de publicações com o termo pesquisado

\begin{tabular}{|c|c|c|c|c|}
\hline Ranking & Base & Produção & $\begin{array}{c}\text { Produções } \\
\text { acumuladas }\end{array}$ & Zona \\
\hline 1 & Scopus (Elsevier) & 12 & 12 & \multirow[b]{2}{*}{ Núcleo } \\
\hline 2 & $\begin{array}{l}\text { Science Citation Index } \\
\text { Expanded (Web of Science) }\end{array}$ & 9 & 21 & \\
\hline 3 & OneFile (GALE) & 7 & 28 & \multirow{5}{*}{ Zona 1} \\
\hline 4 & ScienceDirect (Elsevier) & 6 & 34 & \\
\hline 5 & Elsevier (CrossRef) & 6 & 40 & \\
\hline 6 & $\begin{array}{l}\text { Materials Science \& } \\
\text { Engineering Database }\end{array}$ & 4 & 44 & \\
\hline 7 & Technology Research Database & 3 & 47 & \\
\hline 8 & Engineering Research Database & 3 & 50 & \multirow{13}{*}{ Zona 2} \\
\hline 9 & $\begin{array}{l}\text { Advanced Technologies \& } \\
\text { Aerospace Database }\end{array}$ & 3 & 53 & \\
\hline 10 & $\begin{array}{l}\text { Directory of Open Access } \\
\text { Journals (DOAJ) }\end{array}$ & 3 & 56 & \\
\hline 11 & Springer (CrossRef) & 2 & 58 & \\
\hline 12 & Civil Engineering Abstracts & 2 & 60 & \\
\hline 13 & SpringerLink & 2 & 62 & \\
\hline 14 & $\begin{array}{l}\text { Mechanical \& Transportation } \\
\text { Engineering Abstracts }\end{array}$ & 2 & 64 & \\
\hline 15 & Engineered Materials Abstracts & 1 & 65 & \\
\hline 16 & Oceanic Abstracts & 1 & 66 & \\
\hline 17 & Materials Research Database & 1 & 67 & \\
\hline 18 & $\begin{array}{l}\text { ASFA: Aquatic Sciences and } \\
\text { Fisheries Abstracts }\end{array}$ & 1 & 68 & \\
\hline 19 & Emerald Insight & 1 & 69 & \\
\hline 20 & METADEX & 1 & 70 & \\
\hline
\end{tabular}

Fonte: Elaborada pelos autores

A pesquisa realizada nos bancos de coleção de periódicos apontou que há apenas 70 publicações dentro do período de 20 anos, o que corresponde a uma média de 3,5 trabalhos por ano.

O Gráfico 1 demonstra, em escala logarítmica, uma tendência que compreende uma distribuição de Bradford. 


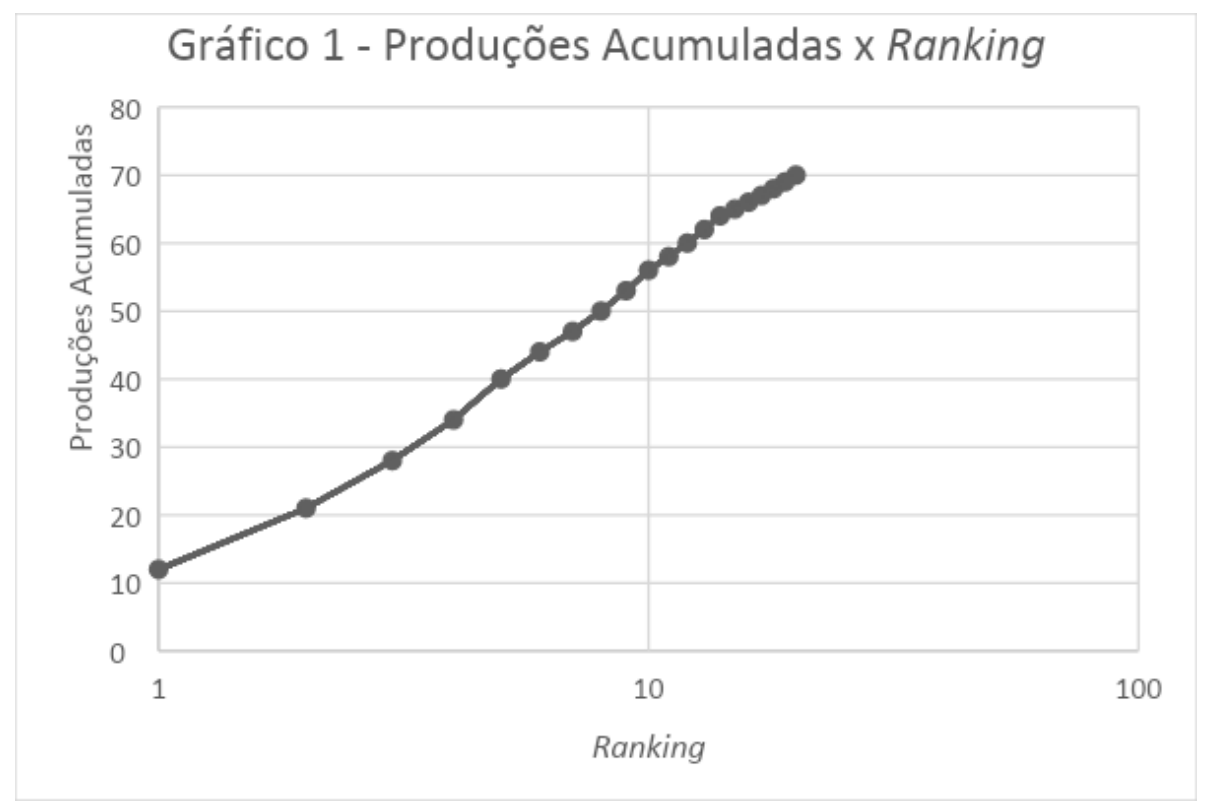

Fonte: Dados da pesquisa. Elaborada pelos autores

As delimitações das Zonas são aferidas por meio do multiplicador de Bradford, que representa a medida de densidade ou dispersão do fenômeno estudado. O multiplicador apresentou entre Zona $1 \mathrm{e}$ Núcleo o produto 2,5 e entre Zona 2 e Zona 1 o produto 2,6, o que demonstra uma boa proporcionalidade.

Nota-se, portanto, que a base Scopus (Elsevier) possui um considerável volume de publicações com os termos "RHVT" ou "VORTEX TUBE" ou "RANQUE-HILSCH" e "CFD" nos títulos, dentro do período e tópico pré-estabelecidos, correspondendo a pouco mais de $17 \%$ de todas as outras bases. Por esta razão, foi utilizado a base Scopus (Elsevier) como referência para o presente trabalho.

\subsection{Pesquisa pelos termos mais utilizados.}

Uma vez definida a base de coleção e os critérios padrões estabelecidos para todas as buscas, foram então pesquisados entre o período de 2000 até 2020 e limitado ao tópico "Engineering", alguns termos destacados na base para verificar qual é o mais utilizado. A Tabela 4 demonstra que o termo "vortex tube" é o mais comumente encontrado no título dos trabalhos.

Tabela 4 - Pesquisa por termo do dispositivo destacado no título

\begin{tabular}{l|c}
\hline \multicolumn{1}{c|}{ Termo do dispositivo } & $\begin{array}{c}\text { Frequência encontrada no } \\
\text { título das publicações }\end{array}$ \\
\hline Vortex tube & 397 \\
\hline Ranque-Hilch & 112 \\
\hline Ranque-Hilsch vortex tube & 96 \\
\hline RHVT & 3 \\
\hline Tubo de vórtice & 1 \\
\hline Tubo de Ranque-Hilsch & 0 \\
\hline Tubo de vórtice de Ranque-Hilsch & 0 \\
\hline
\end{tabular}

Fonte: Elaborada pelos autores 
Também foram pesquisados na base os termos destacados "Numerical simulation", "CFD", "Computation Fluid Dynamics" e "fluidodinâmica computacional", ao que se refere a técnica para validação do tubo de vórtice. A Tabela 5 demonstra que os termos "Numerical simulation" e "CFD" são os mais recorrentes.

Tabela 5 - Pesquisa por termo da técnica destacada no título

\begin{tabular}{l|c}
\hline \multicolumn{1}{c|}{ Termo da técnica } & $\begin{array}{c}\text { Frequência encontrada no } \\
\text { título das publicações }\end{array}$ \\
\hline Numerical simulation & 40937 \\
\hline CFD & 15748 \\
\hline Computation Fluid Dynamics & 18 \\
\hline Fluidodinâmica computacional & 0 \\
\hline
\end{tabular}

Então, verificou-se as combinações dos principais termos "vortex tube", "Ranque-Hilch", "Numerical simulation" e CFD, o resultado é apresentado na Tabela 6.

Tabela 6 - Composição dos termos mais comuns nos títulos

\begin{tabular}{l|c}
\hline \multicolumn{1}{c|}{ Composição dos termos } & $\begin{array}{c}\text { Frequência encontrada no } \\
\text { título das publicações }\end{array}$ \\
\hline "Vortex tube" e "CFD" & 27 \\
\hline "Vortex tube" e "Numerical simulation" & 14 \\
\hline "Ranque-Hilch" e "CFD" & 7 \\
\hline $\begin{array}{l}\text { "Ranque-Hilch" e "Numerical } \\
\text { simulation" }\end{array}$ & 5 \\
\hline
\end{tabular}

Apesar do termo destacado "Numerical simulation" ser 2,6 vezes mais utilizado que o termo destacado "CFD", é encontrado uma quantidade menor quando composto com o termo "vortex tube". Utilizando a composição dos termos: "vortex tube" e "CFD", retornou-se os resultados apresentados na Tabela 7, onde também é possível identificar a quantidade de publicações, seja como autoria ou coautoria.

Tabela 7 - Principais autores que utilizam os termos mais recorrentes

\begin{tabular}{|c|c|c|c|}
\hline $\begin{array}{c}\text { Termo do } \\
\text { dispositivo e } \\
\text { técnica }\end{array}$ & $\begin{array}{c}\text { Frequência } \\
\text { encontrada no } \\
\text { título das } \\
\text { publicações }\end{array}$ & Autor & $\begin{array}{c}\text { Quantidade de } \\
\text { publicações } \\
\text { (autorias e } \\
\text { coautorias) } \\
\end{array}$ \\
\hline \multirow{10}{*}{$\begin{array}{c}\text { vortex tube } \\
\mathrm{e} \\
\mathrm{CFD}\end{array}$} & \multirow{10}{*}{27} & Rafiee, S.E. & 10 \\
\hline & & Sadeghiazad, M.M. & 9 \\
\hline & & Pourmahmoud, N. & 3 \\
\hline & & Bej, N. & 2 \\
\hline & & Hassanzadeh, A. & 2 \\
\hline & & Klein, S.A. & 2 \\
\hline & & Nellis, S.A. & 2 \\
\hline & & Parekh, A.D. & 2 \\
\hline & & Sinhamahapatra, K.P. & 2 \\
\hline & & Thakare, H.R. & 2 \\
\hline
\end{tabular}




\subsection{Periódicos que mais publicam o assunto.}

De acordo com a base Scopus (Elsevier), os periódicos Applied Thermal Enginnering, International Journal Of Heat And Technology e International Journal Of Refrigeration, são as fontes mais dedicadas ao assunto, com três publicações cada dentro do período. A Tabela 8 apresenta em detalhes os resultados obtidos.

Tabela 8 - Ranking dos periódicos mais dedicados ao assunto.

\begin{tabular}{|c|c|c|c|c|}
\hline Ranking & Base & Produção & $\begin{array}{c}\text { Produções } \\
\text { acumuladas }\end{array}$ & Zona \\
\hline 1 & Applied Thermal Engineering & 3 & 3 & \multirow{3}{*}{ Núcleo } \\
\hline 2 & $\begin{array}{l}\text { International Journal Of Heat And } \\
\text { Technology }\end{array}$ & 3 & 6 & \\
\hline 3 & International Journal Of Refrigeration & 3 & 9 & \\
\hline 4 & Energy & 2 & 11 & \multirow{6}{*}{ Zona 1} \\
\hline 5 & $\begin{array}{l}\text { International Journal Of Heat And Mass } \\
\text { Transfer }\end{array}$ & 2 & 13 & \\
\hline 6 & $\begin{array}{l}\text { Iop Conference Series Materials Science } \\
\text { And Engineering }\end{array}$ & 2 & 15 & \\
\hline 7 & Aerospace Science And Technology & 1 & 16 & \\
\hline 8 & Applied Mechanics And Materials & 1 & 17 & \\
\hline 9 & $\begin{array}{l}\text { Collection Of Technical Papers 9th AIAA } \\
\text { ASME Joint Thermophysics And Heat } \\
\text { Transfer Conference Proceedings }\end{array}$ & 1 & 18 & \\
\hline 10 & Engineering Computations Swansea Wales & 1 & 19 & \multirow{9}{*}{ Zona 2} \\
\hline 11 & Frontiers In Heat And Mass Transfer & 1 & 20 & \\
\hline 12 & International Journal Of Ambient Energy & 1 & 21 & \\
\hline 13 & $\begin{array}{l}\text { International Journal Of Low Carbon } \\
\text { Technologies }\end{array}$ & 1 & 22 & \\
\hline 14 & $\begin{array}{l}\text { Journal Of Marine Science And } \\
\text { Application }\end{array}$ & 1 & 23 & \\
\hline 15 & Matec Web Of Conferences & 1 & 24 & \\
\hline 16 & Mechanics And Industry & 1 & 25 & \\
\hline 17 & Scientia Iranica & 1 & 26 & \\
\hline 18 & $\begin{array}{l}\text { Transactions Of The Korean Society Of } \\
\text { Mechanical Engineers } B\end{array}$ & 1 & 27 & \\
\hline
\end{tabular}

Fonte: Elaborada pelos autores

O Gráfico 2 também demonstra, em escala logarítmica, uma tendência que compreende uma distribuição de Bradford, validando a limitação por zonas estabelecidas. 


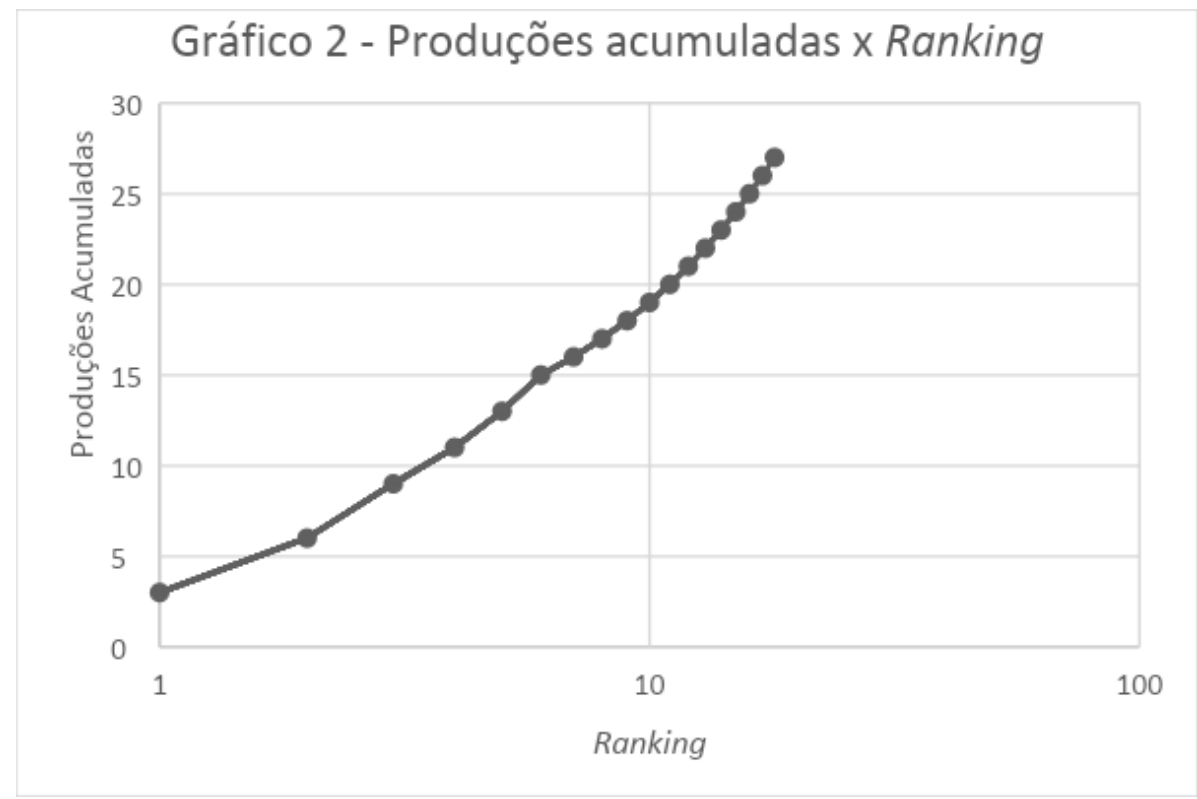

Fonte: Dados da pesquisa. Elaborada pelos autores

\subsection{Investigação do uso dos termos mais utilizados.}

Encontrou-se um total de 27 publicações com o termo "vortex tube" e "CFD". O Gráfico 3 apresenta o volume de publicações com o termo mais utilizado por ano, e que até o momento da pesquisa, não houveram publicações no ano de 2020.

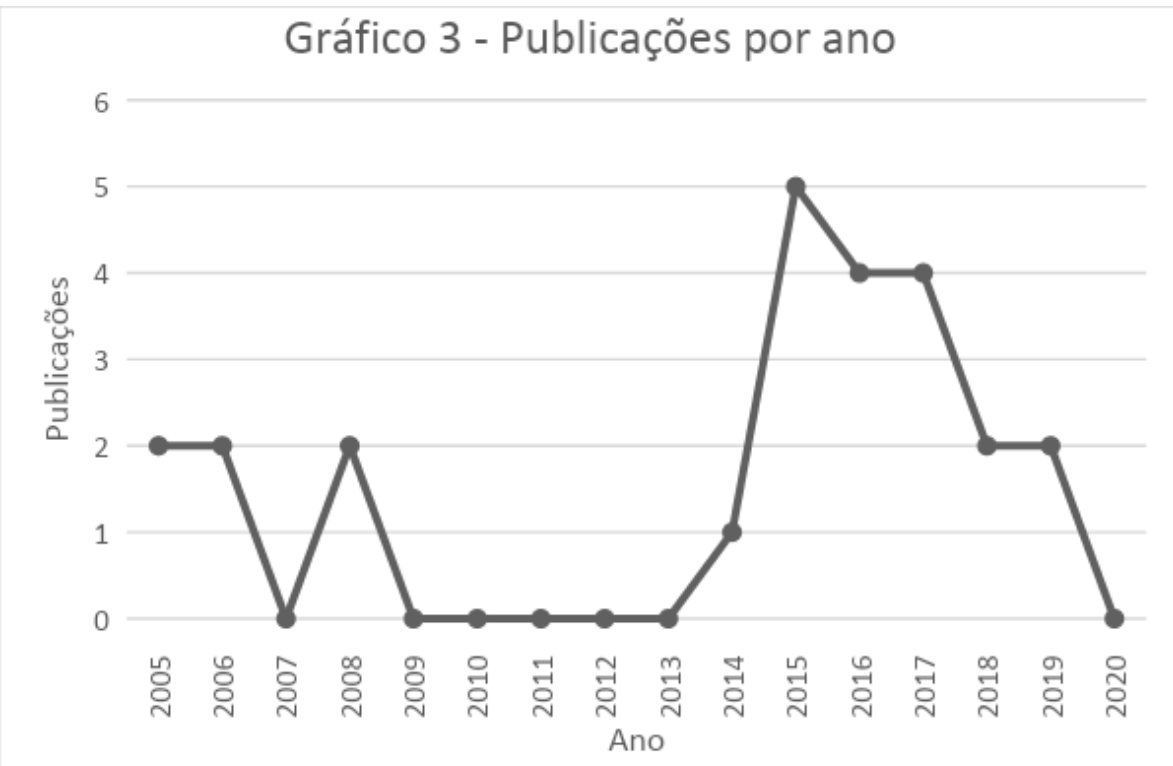

Fonte: Dados da pesquisa. Elaborada pelos autores

É possível observar também que na base Scopus (Elsevier) não houve publicações entre 2000 e 2005, o que poderia aumentar o índice das bases de coleções se ajustado para 2005 como o início para o período. Entre 2009 a 2013 também não há registros de publicações, enquanto que o ápice acontece em 2015, com 5 publicações. 
O Gráfico 4 apresenta o volume de publicações com os termos mais utilizados por país ou território de origem.

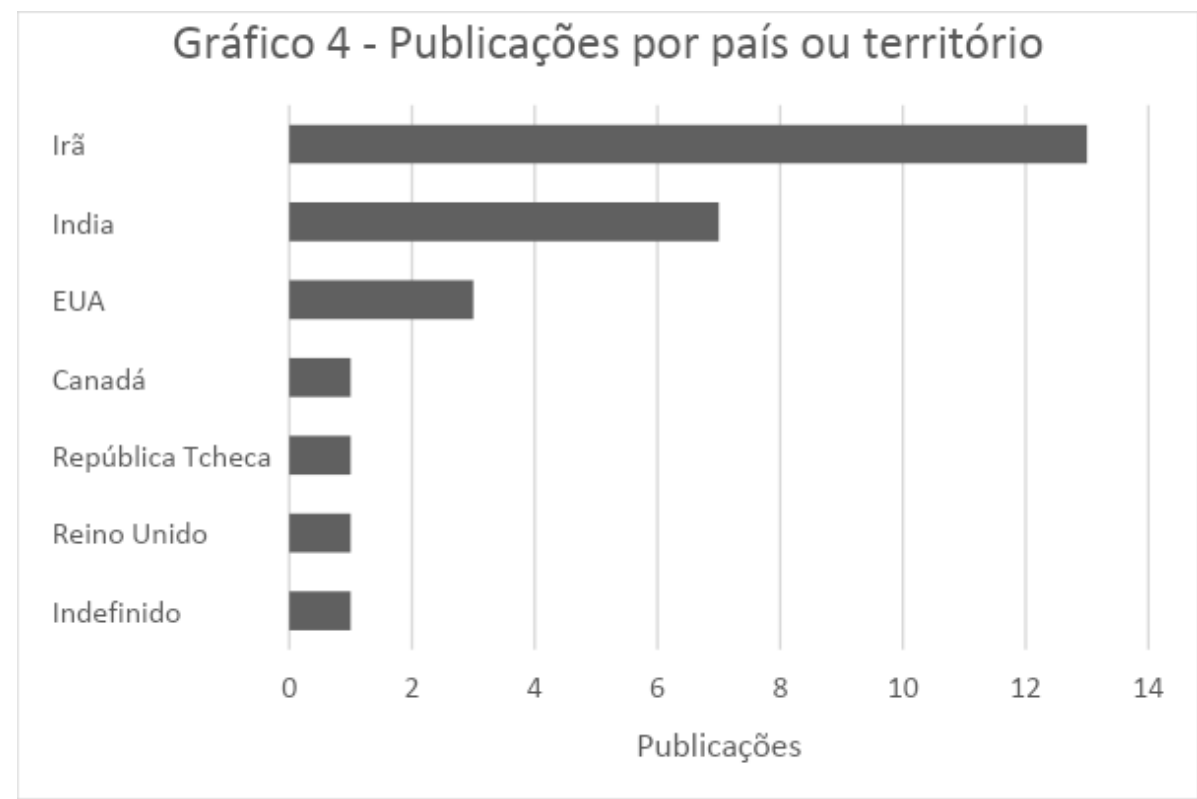

Fonte: Dados da pesquisa. Elaborada pelos autores

O Gráfico 5 apresenta um comparativo dos dez autores e coautores, sem distinção, que mais contribuíram com o termo em seus títulos. O total contabilizado é de quarenta e seis autores/coautores.

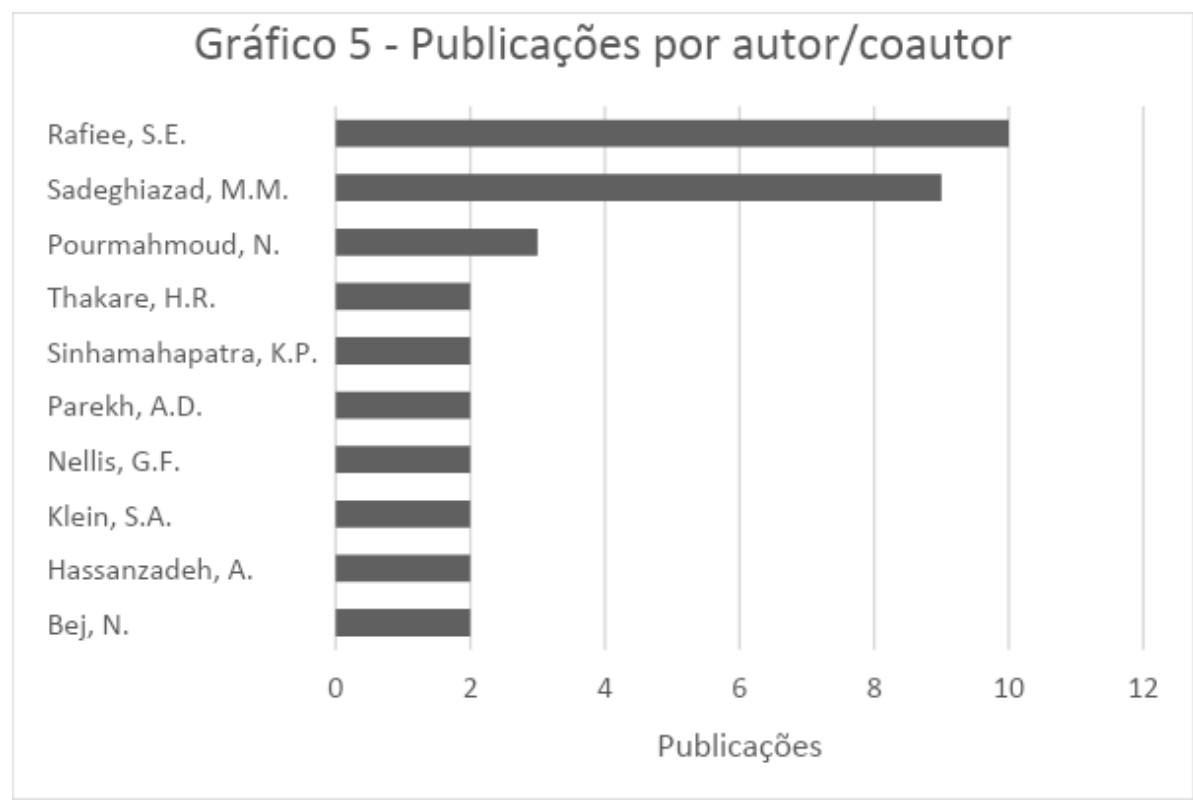

Fonte: Dados da pesquisa. Elaborada pelos autores

A Tabela 9 elenca as dez publicações mais citadas que têm a composição dos termos "vortex tube" e "CFD" em seus títulos e a quantidade total de citações. O Gráfico 6 apresenta o histórico de citações, ano a ano. 
Tabela 9 - Dez artigos mais citados com os termos "vortex tube" e "CFD"

\begin{tabular}{|c|c|c|c|c|}
\hline Título do artigo & Autores & $\begin{array}{c}\text { Ano de } \\
\text { publicação }\end{array}$ & Fonte & Citações \\
\hline $\begin{array}{l}\text { Parametric and internal study of } \\
\text { the vortex tube using a CFD } \\
\text { model }\end{array}$ & $\begin{array}{l}\text { Aljuwayhel, } \\
\text { N.F., } \\
\text { Nellis, G.F., } \\
\text { Klein, S.A. }\end{array}$ & 2005 & $\begin{array}{l}\text { International Journal of } \\
\text { Refrigeration } \\
28(3), \text { pp. } 442-450\end{array}$ & 183 \\
\hline $\begin{array}{l}\text { Comparison of CFD analysis to } \\
\text { empirical data in a commercial } \\
\text { vortex tube }\end{array}$ & $\begin{array}{l}\text { Skye, H.M., } \\
\text { Nellis, G.F., } \\
\text { Klein, S.A. }\end{array}$ & 2006 & $\begin{array}{l}\text { International Journal of } \\
\text { Refrigeration } \\
\text { 29(1), pp. } 71-80\end{array}$ & 151 \\
\hline $\begin{array}{l}\text { CFD analysis and experimental } \\
\text { investigations towards } \\
\text { optimizing the parameters of } \\
\text { Ranque-Hilsch vortex tube } \\
\end{array}$ & Behera, U. et al. & 2005 & $\begin{array}{l}\text { International Journal of } \\
\text { Heat and Mass Transfer } \\
\text { 48(10), pp. 1961-1973 }\end{array}$ & 147 \\
\hline $\begin{array}{l}\text { Experimental study and three- } \\
\text { dimensional }(3 D) \text { computational } \\
\text { fluid dynamics }(C F D) \text { analysis } \\
\text { on the effect of the convergence } \\
\text { ratio, pressure inlet and number } \\
\text { of nozzle intake on vortex tube } \\
\text { performance-Validation and } \\
\text { CFD optimization }\end{array}$ & $\begin{array}{l}\text { Rafiee, S.E., } \\
\text { Rahimi, M. }\end{array}$ & 2013 & $\begin{array}{l}\text { Energy } \\
63 \text {, pp. 195-204 }\end{array}$ & 47 \\
\hline $\begin{array}{l}\text { Experimental and } 3 D C F D \\
\text { investigation on heat transfer } \\
\text { and energy separation inside a } \\
\text { counter flow vortex tube using } \\
\text { different shapes of hot control } \\
\text { valves }\end{array}$ & $\begin{array}{l}\text { Rafiee, S.E., } \\
\text { Sadeghiazad, } \\
\text { M.M. }\end{array}$ & 2017 & $\begin{array}{l}\text { Applied Thermal } \\
\text { Engineering } \\
\text { 110, pp. 648-664 }\end{array}$ & 37 \\
\hline $\begin{array}{l}\text { Experimental investigation \& } \\
\text { CFD analysis of Ranque-Hilsch } \\
\text { vortex tube }\end{array}$ & $\begin{array}{l}\text { Thakare, H.R., } \\
\text { Parekh, A.D. }\end{array}$ & 2017 & $\begin{array}{l}\text { Energy } \\
\text { 133, pp. 284-298 }\end{array}$ & 22 \\
\hline $\begin{array}{l}\text { Three-dimensional CFD } \\
\text { simulation of fluid flow inside a } \\
\text { vortex tube on basis of an } \\
\text { experimental model- The } \\
\text { optimization of vortex chamber } \\
\text { radius }\end{array}$ & $\begin{array}{l}\text { Rafiee, S.E., } \\
\text { Sadeghiazad, } \\
\text { M.M. }\end{array}$ & 2016 & $\begin{array}{l}\text { International Journal of } \\
\text { Heat and Technology } \\
\text { 34(2), pp. 236-244 }\end{array}$ & 22 \\
\hline $\begin{array}{l}3 D \text { cfd exergy analysis of the } \\
\text { performance of a counter flow } \\
\text { vortex tube }\end{array}$ & $\begin{array}{l}\text { Rafiee, S.E., } \\
\text { Sadeghiazad, } \\
\text { M.M. }\end{array}$ & 2014 & $\begin{array}{l}\text { International Journal of } \\
\text { Heat and Technology } \\
\text { 32(1-2), pp. 71-77 } \\
\end{array}$ & 20 \\
\hline $\begin{array}{l}\text { CFD analysis of energy } \\
\text { separation of vortex tube } \\
\text { employing different gases, } \\
\text { turbulence models and } \\
\text { discretisation schemes }\end{array}$ & $\begin{array}{l}\text { Thakare, H.R., } \\
\text { Parekh, A.D. }\end{array}$ & 2014 & $\begin{array}{l}\text { International Journal of } \\
\text { Heat and Mass Transfer } \\
78 \text {, pp. } 360-370\end{array}$ & 20 \\
\hline $\begin{array}{l}\text { Experimental study and } 3 D \\
\text { CFD analysis on the } \\
\text { optimization of throttle angle for } \\
\text { a convergent vortex tube }\end{array}$ & $\begin{array}{l}\text { Rafiee, S.E., } \\
\text { Sadeghiazad, } \\
\text { M.M. }\end{array}$ & 2016 & $\begin{array}{l}\text { Journal of Marine } \\
\text { Science and Application } \\
\text { 15(4), pp. 388-404 }\end{array}$ & 15 \\
\hline
\end{tabular}

Fonte: Elaborada pelos autores 


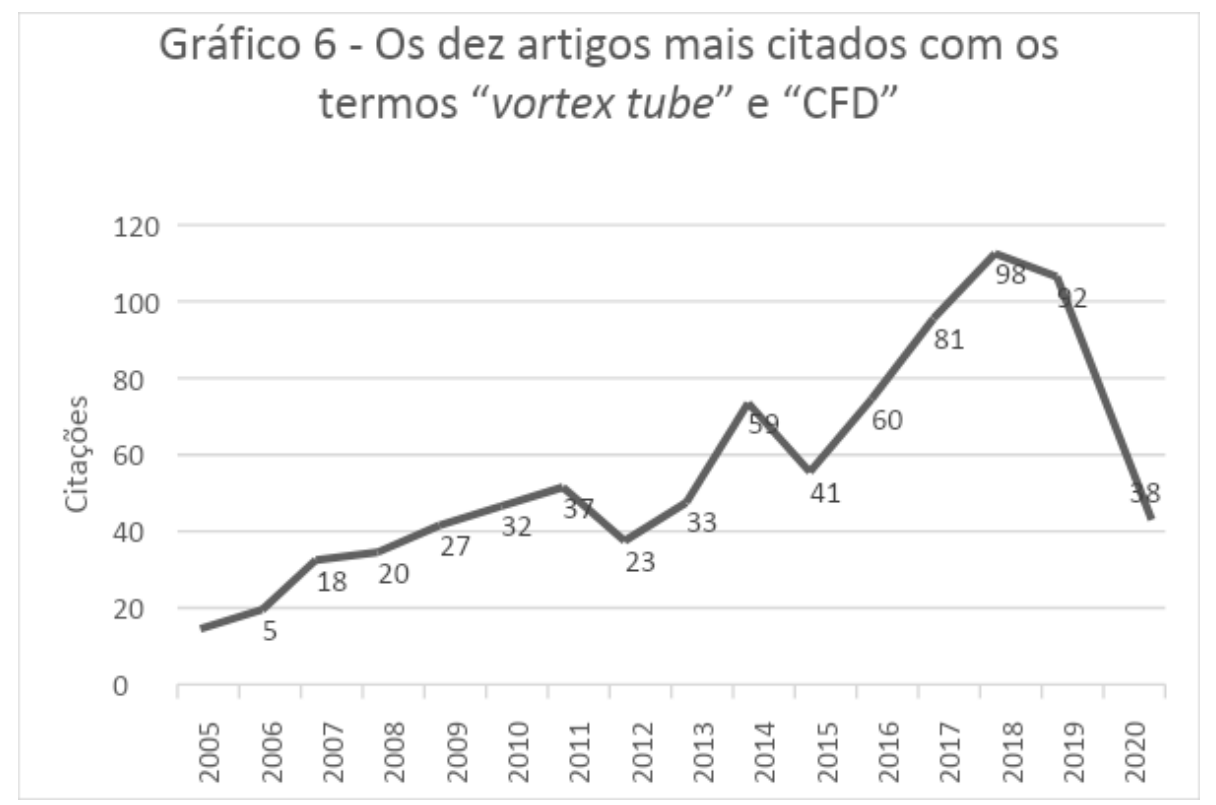

Fonte: Dados da pesquisa. Elaborada pelos autores

Nota-se que o ano de 2018 foi quando houve a maior ocorrência de citações, que, analisando em conjunto com o Gráfico 3, é possível observar que há uma distância de três anos desde o pico das publicações, em 2015. O que é um prazo razoável, reflexo de uma maior visibilidade ao tema e entusiasmando mais pesquisas, entretanto, não se sustenta. Ambos os gráficos começam a imprimir um decréscimo, ainda que os números de citações diminuíram quase 7\% em 2019 em relação ao ano anterior, não é possível extrapolar para 2020 em diante baseado apenas no gráfico de publicações.

A Tabela 10 apresenta a frequência de citações, por autor, nas dez publicações mais citadas.

Tabela 10 - Frequência de autores nas dez publicações mais citadas

\begin{tabular}{l|c}
\hline Autor / Coautor & $\begin{array}{c}\text { Frequência encontrada } \\
\text { nas publicações }\end{array}$ \\
\hline Nellis, G.F. & 334 \\
\hline Klein, S.A. & 334 \\
\hline Aljuwayhel, N.F. & 183 \\
\hline Skye, H.M. & 151 \\
\hline Behera, U. & 147 \\
\hline Paul, P.J. & 147 \\
\hline Kasthurirengan, S. & 147 \\
\hline Karunanithi, R. & 147 \\
\hline Ram, S.N. & 147 \\
\hline Dinesh, K. & 147 \\
\hline Jacob, S. & 147 \\
\hline Rafiee, S.E. & 141 \\
\hline Sadeghiazad, M.M. & 94 \\
\hline Rahimi, M. & 47 \\
\hline Thakare, H.R. & 42 \\
\hline Parekh, A.D. & 42 \\
\hline
\end{tabular}

Fonte: Elaborada pelos autores 
Já a Tabela 11 traz, por ordem de citações, a relação entre a quantidade em que o autor é citado e suas publicações, onde é possível observar suas contribuições e a relevância de seus trabalhos. A Figura 4 é uma visualização do mapa da densidade por publicações e citações gerado por intermédio do software VOSviewer versão 1.6.15.

Tabela 11 - Frequência de autores nas dez publicações mais citadas e quantidade de publicações

\begin{tabular}{l|c|c}
\hline Autor / Coautor & $\begin{array}{c}\text { Quantidade } \\
\text { de citações }\end{array}$ & Publicações \\
\hline Nellis, G.F. & 334 & 2 \\
\hline Klein, S.A. & 334 & 2 \\
\hline Aljuwayhel, N.F. & 183 & 1 \\
\hline Rafiee, S.E. & 176 & 10 \\
\hline Skye, H.M. & 151 & 1 \\
\hline Behera, U. & 147 & 1 \\
\hline Paul, P.J. & 147 & 1 \\
\hline Kasthurirengan, S. & 147 & 1 \\
\hline Karunanithi, R. & 147 & 1 \\
\hline Ram, S.N. & 147 & 1 \\
\hline Dinesh, K. & 147 & 1 \\
\hline Jacob, S. & 147 & 1 \\
\hline Sadeghiazad, M.M. & 129 & 9 \\
\hline Rahimi, M. & 47 & 1 \\
\hline Thakare, H.R. & 42 & 2 \\
\hline Parekh, A.D. & 42 & 2 \\
\hline Pourmahmoud, N. & 14 & 3 \\
\hline
\end{tabular}

Fonte: Elaborada pelos autores

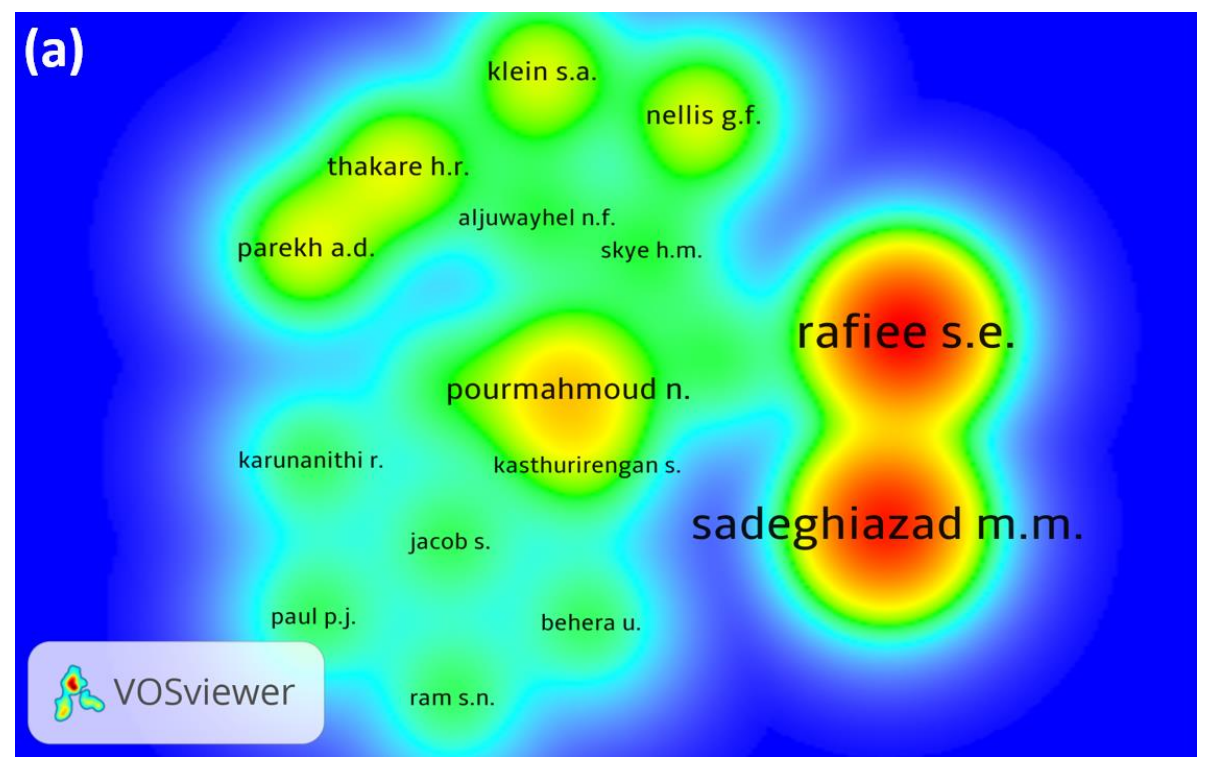




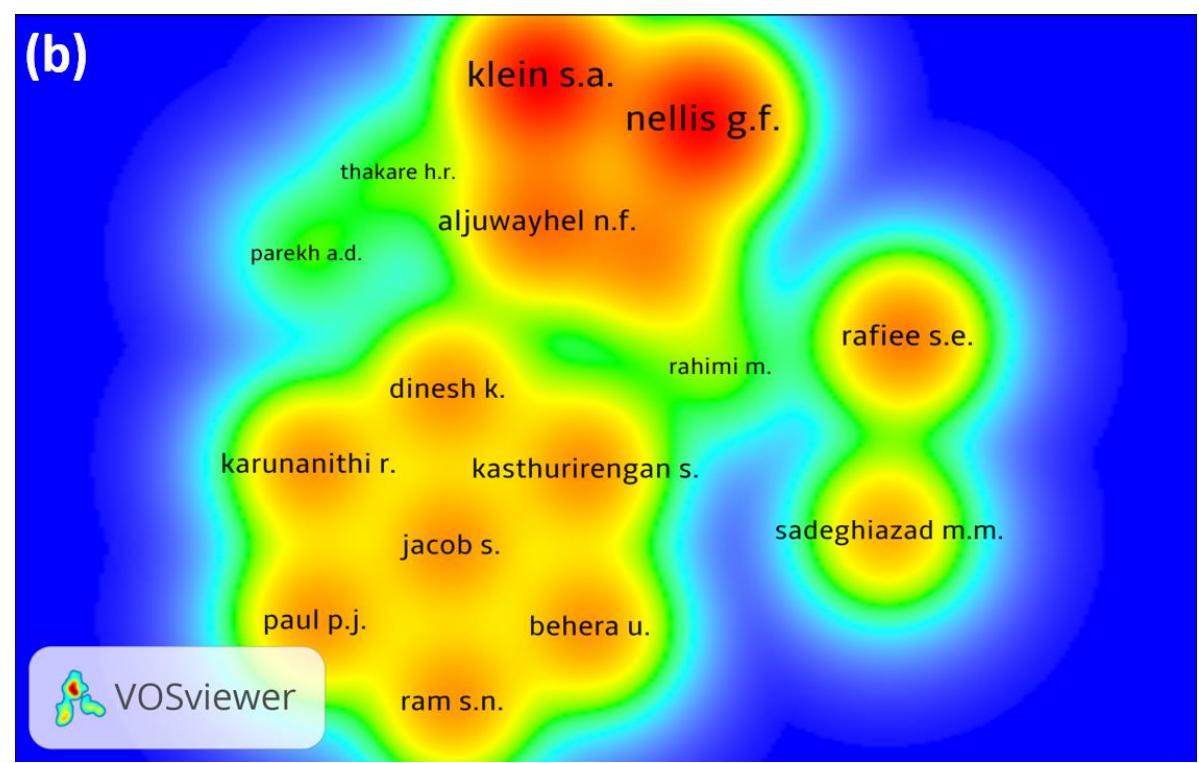

Figura 4 - Mapa da densidade (a) por publicações e (b) por citações. Elaborada pelos autores

Também por intermédio do software VOSviewer versão 1.6.15, obteve-se a Figura 5, que apresenta o relacionamento entre os autores/coautores em média de intensidade de suas publicações e em que foram citados, no período de 2000 a 2020.

\section{(a)}
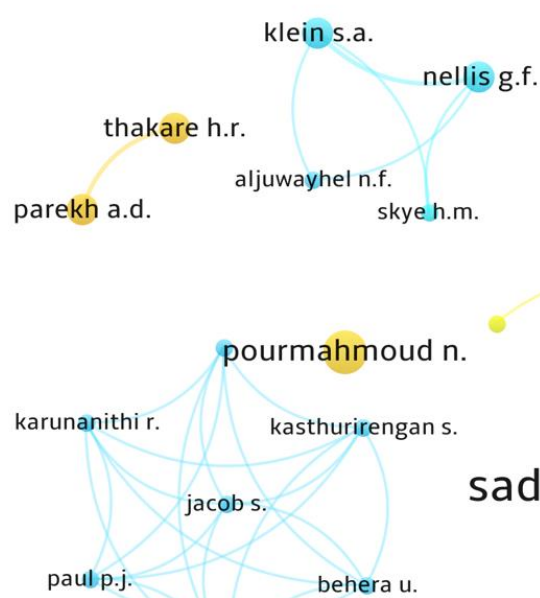

\section{rafiee s.e.}

sadeghiazad m.m.

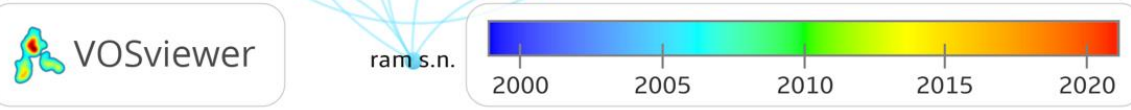




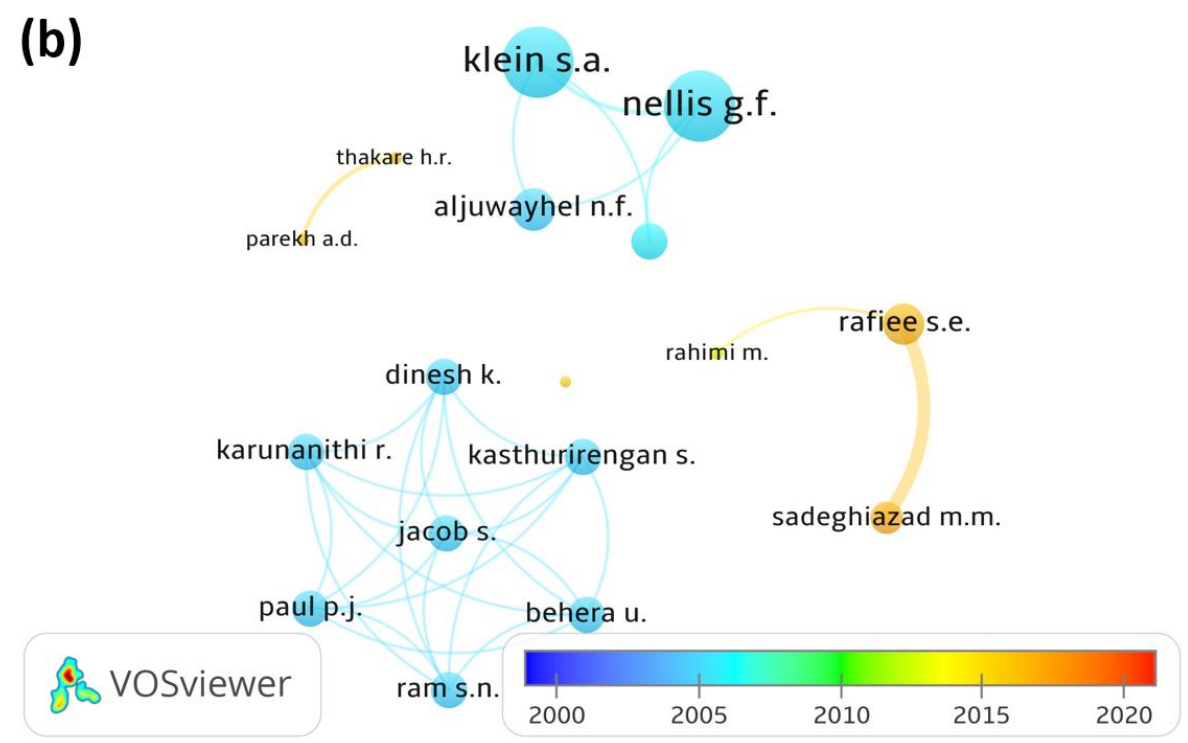

Figura 5 - Relacionamento entre autores/coautores em média de intensidade (a) de publicações e (b) de citações, no período de 2000 a 2020. Elaborada pelos autores

Analisando em conjunto o Gráfico 5, a Tabela 9, a Tabela 10, a Tabela 11, a Figura 4 e a Figura 5, Rafiee, S. E. é quem mais publicou no período com a disponibilização de 10 trabalhos, enquanto que Nellis, G. F. e Klein, S. A. têm as publicações mais citadas.

Já o artigo Parametric and internal study of the vortex tube using a CFD model, de Aljuwayhel, N. F., Nellis, G. F., Klein, S. A., publicado em 2005, é o mais mencionado com 183 citações, isto não necessariamente corresponde ser o mais relevante, pois pode ser reflexo do lapso do início das publicações que até então eram ainda mais escassas, uma vez que o referido foi publicado no primeiro ano em que constam os registros e por conseguinte está a mais tempo disponível.

\section{Conclusões.}

Por meio do método utilizado para a elaboração desta pesquisa bibliométrica foi possível identificar que, até o ano de 2020, o assunto com a composição dos termos "tubo de vórtice" e "fluidodinâmica computacional", ainda que em suas variações, é pouco utilizado.

Também foi observado que as publicações identificadas neste trabalho têm direcionado suas pesquisas em compreender o fenômeno que ocorre no interior do "vortex tube" e para isso a ferramenta "CFD" se apresenta como fundamental, sendo capaz de retornar resultados fidedignos às experimentações. A maioria destas publicações são direcionadas em verificar desde geometrias alternativas, como alterações na válvula de saída quente até a avaliação da influência em diversos modelos numéricos computacionais, mas não é possível observar uma tendência específica em uma linha de pesquisa, o que indica que ainda pouco se conhece deste dispositivo.

Congruente à Lei de Bradford, fica evidente a concentração da maior parte do assunto pesquisado em poucos periódicos. Também é percebido que o número de publicações vem diminuindo nos últimos quatro anos, o que pode representar um desinteresse ao assunto ou uma limitação da atual tecnologia.

É importante ressaltar que o RHVT é uma realidade e já é comercializado nos dias de hoje, isso também pode justificar a falta de entusiasmo para novas pesquisas sob a ótica de se ter estabilizado num conformismo em torno da análise entre custo e benefício de sua aplicação pelo mercado. 


\section{Referências.}

ALJUWAYHEL, N. F.; NELLIS, G. F.; KLEIN, S. A. Parametric and internal study of the vortex tube using a CFD model. International Journal Of Refrigeration, v. 28, n. 3, p.442-450, maio 2005. Elsevier $\mathrm{BV}$.

BAZGIR, A.; KHOSRAVI-NIKOU, M.; HEYDARI, A. numerical CFD analysis and experimental investigation of the geometric performance parameter influences on the counter-flow Ranque-Hilsch vortex tube (C-RHVT) by using optimized turbulence model. Heat and mass transfer, v. 55, n. 9, p.25592591, 13 Mar. 2019. Springer Science and Business Media LLC.

BRASIL. Ministério da Educação. Coordenação de Aperfeiçoamento de Pessoal de Nível Superior do Ministério da Educação (CAPES): portal de periódicos. Disponível em: http://www.periodicos.capes.gov.br/. Acesso em: 05 jun. 2020.

DÖRR, É. A. B. Dimensionamento de um tubo de vórtice para utilização na refrigeração de usinagens. 2017. 95 f. TCC (Graduação) - Curso de Engenharia Mecânica, Universidade Regional do Noroeste do Estado do Rio Grande do Sul - UNIJUÍ, Panambi, 2017.

EIAMSA-ARD, S.; PROMVONGE, P. Review of Ranque-Hilsch effects in vortex tubes. Science Direct: Renewable and Sustainable Energy Reviews, v. 12, n. 7, p.1822-1841, Sept. 2008. Elsevier BV

Elsevier Editora Ltda. Disponível em: http://www.elsevier.com. Acesso em: 05 jun. 2020.

ITAO, D. C. Estudo de um sistema alternativo de ar condicionado automotivo baseado na aplicação de tubos de vórtice utilizando o conceito de regeneração energética. 2005. 113 f. Dissertação (Mestrado) Curso de Mestrado Profissionalizante em Engenharia Automotiva, Universidade de São Paulo, São Paulo, 2005.

LIMA, S. H. O.; LEOCÁDIO, A. L. Mapeando a produção científica internacional sobre inovação aberta. Revista Brasileira de Gestão e Inovação, [S.L.], v. 5, n. 2, p. 181-208, 5 jan. 2018. Universidade Caxias do Sul.

MARAGON, D. A. Estudo e análise de um tubo de vórtices. 2016. 43 f. TCC (Graduação) - Curso de Engenharia de Controle e Automação, Centro de Ciências Exatas e Tecnológicas, Universidade de Caxias do Sul, Caxias do Sul, 2016.

MOREIRA, P. S. C.; GUIMARÃES, A. J. R.; TSUNODA, D. F. Qual ferramenta bibliométrica escolher? Um estudo comparativo entre softwares. P2P E INOVAÇÃO, v. 6, n. 2, p. 140-158, 31 mar. 2020.

MURAKAMI, R. H. Determinação do valor do coeficiente de vazão de válvulas industriais através da dinâmica de fluidos computacional. 2010. 118 f. Dissertação (Mestrado) - Curso de Mestrado em Processos Industriais, Instituto de Pesquisas Tecnológicas do Estado de São Paulo - IPT, São Paulo, 2010.

PINHEIRO, L. V. R. Lei de Bradford: uma reformulação conceitual. 1982. 116 f. Dissertação (Mestrado) - Curso de Mestrado em Ciência da Informação, Instituto Brasileiro de Informação em Ciência e Tecnologia, Universidade Federal do Rio de Janeiro, Rio de Janeiro, 1982.

; CHALHUB, T.; NISENBAUM, M. A. Desbravando caminhos de navegantes do portal Canal Ciência via metrias de informação. Liic em Revista, Rio de Janeiro, v. 9, n. 1, p. 237-254, maio 2013.

QUEVEDO-SILVA, F. et al. Estudo Bibliométrico: orientações sobre sua aplicação. Revista Brasileira de Marketing, São Paulo, v. 15, n. 2, p. 246-262, jun. 2016.

RANQUE, G. J. Method and apparatus for obtaning from a fluid under pressure two currents of fluids at different temperatures. Titular: United States Patent Office. FR n. 1.952.281. Depósito: 6 Dez. 1932. Concessão: 27 Mar. 1934.

VOSviewer. Disponível em: http://www.vosviewer.com. Acesso em: 07 jun. 2020. 
YILMAZ, M. et al. A review on design criteria for vortex tubes. Heat Mass Transfer, v. 45, n. 5, p.613632, mar. 2009. Springer Science and Business Media LLC. 